\title{
PRESSUPOSTOS PRAGMÁTICOS DA LINGUAGEM E INTERPRETAÇÃO MORAL DA CONSTITUIÇÃO
}

PRAGMATIC PREMISES OF CONSTITUTIONAL LANGUAGE AND MORAL INTERPRETATION

PRESUPUESTOS PRAGMÁTICOS DEL LENGUAJE E INTERPRETACIÓN MORAL DE LA CONSTITUCIÓN

Rachel Nigro ${ }^{1}$

Resumo: Este artigo pretende apresentar alguns elementos da filosofia pragmática da linguagem, como a noção de jogo de linguagem e de ato de fala, os quais orientam a nova hermenêutica constitucional-democrática. Por meio da desconstrução da oposição entre "ativismo" e "judicialização" que norteia o debate sobre a jurisdição constitucional no Brasil, argumento que a interpretação de dispositivos constitucionais moralmente carregados, como os que expressam os direitos fundamentais, implica uma atividade complexa de reconstrução de sentido. Com apoio na filosofia pragmática da linguagem e na teoria interpretativa de

1 Doutora em Filosofia e mestre em Direito pela PUC-Rio, Professora dos departamentos de Direito e Filosofia da Pontifícia Universidade Católica do Rio de Janeiro - PUC-Rio - Brasil. rachel.nigro@gmail.com. 
Dworkin, pretendo destacar a importância da deliberação - que envolve a argumentação prático-moral - reservada para a corte constitucional no atual modelo democrático.

Palavras-chaves: Democracia deliberativa. Corte constitucional. Interpretação constitucional. Filosofia pragmática da linguagem. Ativismo Judicial. Argumentação moral.

Abstract: This paper presents some elements of the pragmatic philosophy of language, such as the notion of play of/in language and speech acts, which influence the new constitutional-democratic hermeneutic. Through the deconstruction of the opposition between judicial activism and judicialization that guides the debate on constitutional jurisdiction in Brazil, this paper aims to show that the interpretation of the moral provisions of the constitution, such as those that express the fundamental rights, involves a complex activity of reconstructing the text. With support from the notions of pragmatics and some features of Dworkin's theory of interpretation of law, I emphasize the importance of deliberation - which involves moral argumentation - reserved for the constitutional courts in today's constitutional democracy.

Keywords: Deliberative Democracy. Constitutional courts. Constitutional interpretation. Pragmatic philosophy of language. Judicial Review. Moral argumentation.

Resumen: Este artículo pretende presentar algunos elementos de la filosofía pragmática del lenguaje, tal como la noción de juego de lenguaje y del acto del habla, los que orientan la nueva hermenéutica constitucional democrática. Por medio de la desconstrucción de la oposición entre "activismo" y "judicialización" que polariza el debate sobre la jurisdicción constitucional en Brasil, el autor argumenta que la interpretación de dispositivos constitucionales moralmente cargados, como los que expresan los derechos fundamentales, implica una actividad compleja de reconstrucción de sentido. Con apoyo en la filosofía pragmática del lenguaje y en la teoría interpretativa de Dworkin, se pretende destacar la importancia de la deliberación - que involucra la argumenta- 
ción práctico-moral - reservada para la corte constitucional en el actual modelo democrático.

Palabras clave: Democracia deliberativa. Corte constitucional. Interpretación constitucional. Filosofía pragmática del lenguaje. Activismo Judicial. Argumentación moral.

\section{INTRODUÇÃO}

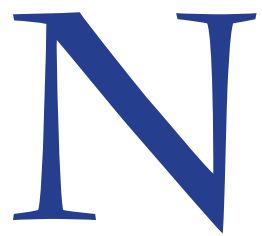

os últimos anos o Supremo Tribunal Federal decidiu casos polêmicos que trouxeram à tona o papel crescente desempenhado por uma corte constitucional nas democracias constitucionais contemporâneas. Tal fenômeno é recente no Brasil, tendo em vista a relativa juventude de nossa Constituição, cujo desenho institucional aproximou o STF de uma corte constitucional. Mas o debate acerca do papel de cortes constitucionais no desenho institucional das democracias contemporâneas é vasto e complexo. ${ }^{2}$

Além dos desafios político-institucionais que acompanham a jurisdição constitucional no atual Estado democrático de Direito, como a revisão da teoria da separação dos poderes e da democracia, a atuação da Corte suprema também exige uma nova perspectiva sobre a interpretação constitucional. Com a constitucionalização do Direito, a velha ideia de sistematicidade do Direito Positivo ganha novos contornos e permite uma inédita expansão do sistema jurídico. Se a ordem jurídica define-se como um sistema dotado de unidade e se a Constituição é responsável por essa unidade, então é forçoso reconhecer

2 Este artigo busca apenas destacar o papel da Corte suprema como instituição que exerce funções políticas, mesmo que não se possa afirmar que o STF seja hoje uma legítima corte constitucional. A distinção entre a atuação 'ativista' de uma corte suprema como o STF e 'ativismos judiciais' em geral, rótulo que envolve a atuação de juízes monocráticos e de tribunais infraconstitucionais na aplicacão direta de princípios constitucionais como fundamento jurídico de suas decisões, não será objeto deste texto. Portanto, os possíveis efeitos sistêmicos indesejados causados pela atuação 'ativista' do STF, tendo em vista o controle misto de constitucionalidade adotado pelo desenho institucional brasileiro, não serão discutidos. Para um aprofundamento sobre a singularidade da adjudicação constitucional e o vínculo entre legitimidade representativa da Corte e qualidade da deliberação, ver MENDES, Conrado Hubner Constitutional Courts and Deliberative Democracy. Oxford University Press, 2013. 
que os diferentes ramos do Direito constituem subsistemas cuja unidade é garantida pela Constituição que dita os valores e fins que devem ser observados e promovidos pelo conjunto do ordenamento. ${ }^{3}$

Nesse sentido, a interpretação constitucional continua sendo uma espécie do gênero interpretação jurídica, mas ganha contornos tão peculiares que leva a suspeitar que toda a interpretação jurídica hoje envolve potencialmente uma argumentação constitucional e, consequentemente, o uso de dispositivos moralmente carregados. Nesse sentido, escreve Barroso:

tais especificidades quanto à posição hierárquica, à linguagem, às matérias tratadas e ao alcance político fazem com que a interpretação constitucional extrapole os limites da argumentação puramente jurídica. De fato, além, das fontes convencionais, como o texto da norma e os precedentes judiciais, o intérprete constitucional deverá ter em contra considerações relacionadas à separação de poderes, aos valores éticos da sociedade e à moralidade política. A moderna interpretação constitucional, sem desgarrar-se das categorias do Direito e das possibilidade e limites dos textos normativos. Ideias como interpretação evolutiva, leitura moral da Constituição e interpretação pragmática inserem-se nessa ordem de considerações. ${ }^{4}$

Considerando esse complexo pano de fundo, é forçoso entender a ascensão do Judiciário de modo mais amplo, isto é, como efeito da expansão do Estado Social intervencionista que legisla para o futuro trazendo consigo uma maior carga de indeterminação do direito, ou seja, promessas, bens, objetivos e valores plurais de difícil conciliação. ${ }^{5}$

Assim, a partir do paradigma deliberativo do direito e da democracia, este artigo pretende apresentar alguns elementos da filosofia pragmática da linguagem, como a noção de jogo de linguagem e de ato de fala, que estão na base de muitas teorias da argumentação jurídica. Nesse sentido, na primeira seção do artigo, "A interpretação Constitucional entre a Judicialização e o Ativismo", será desconstruída a oposição entre "ativismo" e "judicialização", que norteia o debate

3 BARROSO, Luis Roberto. Curso de Direito Constitucional Contemporâneo. São Paulo: Saraiva, 2015. p. 329

4 BARROSO, Luis Roberto. Curso de Direito Constitucional Contemporâneo, p. 307.

5 HABERMAS, Jürgen. Direito e Democracia II, Rio de Janeiro: Tempo Brasileiro, 1997, p. 174. 
sobre a jurisdição constitucional do Brasil, no intuito de mostrar que a disputa entre os dois rótulos empobrece o debate e oculta o que está realmente em jogo: a argumentação moral subjacente à interpretação constitucional. ${ }^{6}$

Na segunda seção, "Filosofia pragmática da linguagem e interpretação constitucional", a partir do pressuposto pragmático de que toda interpretação pressupõe uma reconstrução de sentido, serão apresentados alguns elementos da teoria interpretativa de Dworkin, desenvolvida sobretudo após a publicação de "O Império do Direito", cujo autor argumenta que não somente o direito como prática social é profundamente interpretativo (e, em parte, valorativo), mas também que qualquer teoria sobre a natureza do direito é necessariamente interpretativa e possui uma inexorável dimensão moral, especialmente revelada nas argumentações dos casos difíceis. ${ }^{7}$

$\mathrm{Na}$ terceira parte do texto, "Uma versão pragmática da interpretação constitucional", apresentam-se duas noções centrais da filosofia pragmática que subjazem as diversas teorias contemporâneas sobre interpretação: o "jogo de linguagem" de Wittgenstein e o "ato de fala" de Austin, buscando associá-las às diversas teorias da argumentação jurídica contemporânea, como as desenvolvidas por Neil MacCormick, Manuel Atienza e Robert Alexy, além de Ronald Dworkin.

Ao final, algumas notas conclusivas relacionando ativismo, democracia e direitos fundamentais e articulando os principais pontos do artigo que podem ser encontrados na seguinte passagem de Habermas: "Especialmente quando envolver

6 Como o objetivo central deste artigo é apenas apresentar as bases pragmáticas que subjazem algumas das principais teorias contemporâneas sobre a interpretação e a argumentação jurídicas, não se faz necessário uma adesão completa à teoria do direito dworkiana. Por exemplo, sobre a polêmica distinção 'lógica' entre regras e princípios, basta a conclusão não essencialista de que os princípios jurídicos ocupam um espaço intermediário entre as regras jurídicas e os princípios morais e que obtêm sua validade de uma combinação de considerações baseadas na fonte (fatos baseados em decisões passadas) e no conteúdo (argumentos morais). Sobre a tese da separação entre Direito e Moral, bastam certos insigths compartilhados, inclusive pelo positivismo inclusivo, como a opinião de que a moralidade e a validade jurídicas são intimamente relacionadas. Para um panorama do debate em teoria do Direito, ver MARMOR, Andrei. A natureza do direito in Revista Direito, Estado e Sociedade, $n^{\circ}$ 42. PUC-Rio, 2013.

7 Reitera-se que a aceitação desta tese dworkiana independe da concordância com a opinião de Dworkin sobre uma possível "natureza" interpretativa da teoria do direito ou dos detaIhes de sua teoria da interpretação. Com efeito, a tese esboçada em "O Império do Direito" rechaça a possibilidade de uma teoria geral sobre a natureza do direito que se mantenha moralmente neutra. 
a tensão entre direitos fundamentais e soberania popular, não é possível entender a emergência da nova ordem jurídica constitucional se não compreendermos o papel do tribunal constitucional na defesa de direitos fundamentais, em cujas decisões aparece a problemática da indeterminação do direito". 8

\section{A INTERPRETAÇÃO CONSTITUCIONAL ENTRE A JUDICIALIZAÇÃO E O ATIVISMO}

Sabe-se que a origem da ideia de um controle judicial sobre o legislador possui uma longa história. ${ }^{9}$ Para os fins deste texto, vale remarcar que a expressão "revisão judicial" ganhou notoriedade quando foi usada para qualificar a atuação da Suprema Corte norte-americana durante os anos em que foi presidida por Earl Warren, entre 1954 e 1969. Ao longo desse período, o controverso Judicial Review provocou uma revolução profunda e silenciosa em relação a inúmeras práticas políticas nos Estados Unidos, gerando uma grande literatura sobre o assunto.

Já na Europa, a partir do século XX, a reconstitucionalização dos Estados estimulou uma nova teoria constitucional, ${ }^{10}$ sobretudo a partir da interpretação da Constituição de Bonn (1949) e de suas cláusulas inatingíveis. A Corte Constitucional alemã produziu, a partir de então, uma fecunda reflexão sobre os direitos fundamentais a qual influenciou sobremaneira a terceira onda constitucional do século XX, Portugal (1976), Espanha (1978) e Brasil (1988), com suas Constituições dirigentes pós-autoritárias. ${ }^{11}$

8 HABERMAS, Jürgen. Direito e Democracia II, p. 304.

9 Para um estudo detalhado sobre o aspecto multidimensional do ativismo judicial, sua origem no constitucionalismo norte-americano, assim como sua ocorrência em outros países, seus limites e contornos no STF, ver AZEVEDO CAMPOS, Carlos Alexandre. Dimensões do Ativismo Judicial do STF. Rio de Janeiro: Forense, 2014.

10 Parte desse debate já foi rotulado como "pós-positivismo", especialmente o enfoque sobre a normatividade dos princípios constitucionais e a ponderação como novo método para sua aplicação. Utiliza-se aqui a expressão "novo constitucionalismo" para ir além de tais rótulos problemáticos e fazer referência também ao imbricamento entre teoria do direito e filosofia moral que as atuais democracias constitucionais exigem das teorias da argumentação jurídica.

11 Considera-se que o marco de nascimento do controle judicial sobre o legislador (Judicial Review) seja o caso da Suprema Corte norte-americana Marbury v. Madison de 1803, em que o Juiz Marshall interpretou, a partir da noção de Supremacia da Constituição, que ao Judiciário compete sua guarda. Cf. CAPPELLETTI, $\mathbf{O}$ controle judicial de constitucionalidade das leis no direito comparado. 2. ed. Porto Alegre: Fabris, 1999. 
No Brasil, por razões diversas, muitos criticam o protagonismo que o Judiciário assumiu nas últimas duas décadas, o que faz com que o rótulo "ativismojudicial" tornese um termo "guarda-chuva" para designar todas as decisões com as quais os críticos não concordem, tornando a expressão muito vaga para ser usada de modo eficaz na comunicação. Parte da crítica ao "ativismo do STF" pauta-se pela diferenciação entre dois tipos de decisões: aquelas que são consideradas como consequência legítima da judicialização das relações sociais e da nova ordem constitucional e aquelas consideradas abusivas ou que extrapolam os limites da competência judicial e invadem o "âmbito político". Segundo Barroso, é preciso diferenciar, por um lado: i) uma leitura ativa do texto constitucional derivada da força normativa dos princípios e da evidente faceta dirigente da nossa Carta; e, por outro lado: ii) a extrapolação dos limites a ele circunscritos, o desrespeito ao seu núcleo semântico essencial. ${ }^{12}$

Apesar das tentativas de classificação, o termo "ativismo judicial" tem sido utilizado com maior frequência para expressar o temor de uma "supremocracia", ou seja, de uma supremacia absoluta do órgão máximo do poder judiciário. Assim considerado, o ativismo se distinguiria da judicialização por "fugir das amarras legais" e por propugnar a imposição de condutas ou de abstenções ao legislador e ao poder público. Além disso, muitos críticos argumentam que a "atitude pró-ativa" perante o texto conduz à indesejável aplicação direta de dispositivos abertos da Constituição às situações que não foram "expressamente" contempladas em seu texto e à declaração de inconstitucionalidade de leis com base em critérios "menos rígidos" de violação da Constituição.

Desse modo, na maior parte das vezes, ao classificar determinada decisão como ativista, busca-se informar que o juiz extrapolou os limites de sua função, isto é, que transbordou sua competência e invadiu indevidamente a esfera do legislador ao interpretar a Constituição de modo expansivo ou desviar de uma determinada interpretação estabelecida. Por outro lado, afirmar que uma questão está judicializada significa apenas dizer que o Judiciário é obrigado a atuar por determinação constitucional, mesmo que tal atuação pareça incoveniente. ${ }^{13}$

12 BARROSO, Luis Roberto. Judicialização, ativismo judicial e legitimidade democrática, 2008. Disponível em: http://www.oab.org.br/editora/revista/users/revista/ $1235066670174218181901 \mathrm{pdf}$

13 Para uma crítica da nova ordem constitucional que tornou o STF muito poderoso, ver AR- 
Assim, a razão da distinção entre ativismo e judicialização estaria no fato de a segunda simplesmente responder às demandas impostas pela ordem constitucional estabelecida na Carta de 1988; enquanto que atuar de modo ativista seria ir além dos limites da competência descrita no texto e usurpar funções exclusivas do legislador. Tal oposição pressupõe assim que seria possível estabelecer critérios claros, neutros e imparciais sobre os limites interpretativos dos dispositivos constitucionais que determinam as funções das instituições, limites esses que não dependeriam do conteúdo da questão nem dos usos diversos que se pode fazer das expressões linguísticas usadas do texto em disputa.

Para a visão pragmática da linguagem, uma distinção como esta funcionaria apenas nos casos paradigmáticos, deixando os verdadeiros casos difíceis à mercê das opiniões revestidas de argumentos vazios. Nesse sentido, a oposição entre 'judicialização' (aceitável e legítimo) e 'ativismo' (ideologia inaceitável) que organiza o debate acerca da jurisdição constitucional no Brasil acaba não dizendo muita coisa sobre os reais limites interpretativos do texto, nem sobre as razões que justificam decisões ativistas. E pior, tal dicotomia ainda encobre o cerne da questão: a inevitável leitura moral da constituição e sua vinculação com a democracia deliberativa. ${ }^{14}$

Os dispositivos que geram as maiores disputas interpretativas, sejam eles classificados como princípios ou como regras, ${ }^{15}$ são estruturalmente vagos e indeterminados e trazem à tona a tensão entre soberania popular e a jurisdição constitucional, sobretudo nas chamadas decisões 'contra-majoritárias', isto é, quando a corte atua ativamente em defesa de direitos fundamentais de minorias. No caso brasileiro, diversos casos julgados recentemente pelo Supremo Tribunal Federal (STF) envolveram questões de moralidade, de política e de "moralidade

GUELHES, Diego Werneck. Carta criou STF poderoso que muda dinâmica política, Artigo Jornal Valor - 3 de outubro de 2013.

14 Conrado Hubner Mendes ressalta a clausura em que se encontra o debate sobre jurisdição constitucional e política no Brasil, cujos "defensores" do ativismo contribuem para a polarização do debate. Sobre o papel da corte constitucional como deliberador qualificado para participar da deliberação política das democracias atuais, ver MENDES, Conrado Hubner. Constitutional Courts and Deliberative Democracy, p. 4.

15 Para uma visão da distinção entre princípios e regras como consequência do novo modelo constitucional brasileiro, ver NEVES, Marcelo. Entre Hidra e Hércules - princípios e regras constitucionais. São Paulo: Martins Fontes, 2013. 
política" quefomentaram uma intensa discussão sobre o papel a ser desempenhado por uma corte constitucional nas democracias contemporâneas.

Podem-se destacar, nesse sentido, os 'casos difíceis', por muitos considerados como 'ativistas', ${ }^{16}$ decididos recentemente pelo STF e que envolveram uma leitura moral da Constituição: i) ADIN 186 (Cotas), que decidiu pela constitucionalidade das políticas de ação afirmativa a partir de uma interpretação do princípio da igualdade (art. 50, caput, CF), ii) ADPF 54 (Anencefalia), que se derivou do princípio da dignidade humana (art.1일 , III), assim como de um conceito atípico de vida, a possibilidade de antecipação terapêutica do parto de fetos anencéfalos; iii) ADIN 4578 (Ficha Limpa), que relativizou a leitura do art. $5^{\circ}$ LVII - princípio da presunção de inocência - que havia sido alargado para o âmbito eleitoral; iv) ADIN 153, sobre a constitucionalidade da Lei da Anistia, em que em nome da deferência ao legislador ordinário, o STF não aceitou pedido de inconstitucionalidade dos dispositivos que anistiavam crimes de tortura; v) ADIN 4650, a maioria dos ministros declararam votos contrários a o financiamento empresarial de campanhas eleitorais com base numa concepção moral de democracia. Tais exemplos mostram não apenas o papel dos princípios constitucionais na argumentação do STF, mas também na justificação de sua legitimidade como intérprete supremo do texto constitucional. Sobre esse entrelaçamento entre a interpretação constitucional e a democracia, Habermas lembra que "não é possível entender a emergência da nova ordem jurídica constitucional se não compreendermos o papel do tribunal constitucional na defesa de certos direitos, em cujas decisões aparece a problemática da indeterminação do direito". ${ }^{17}$

Nesse sentido, especialmente quando há tensão entre direitos fundamentais e soberania popular, a interpretação constitucional de dispositivos principiológicos é indissociável de uma argumentação prática moral e, portanto, apenas uma teoria que reconhece a leitura moral poderá revelar a disputa pelo sentido dos valores que são subjacentes a esses princípios e, pelo menos, tornar as decisões

16 Ver, por exemplo, a crítica de Lênio Streck quanto à decisão da Adpf 132, que garantiu os direitos civis de casais homoafetivos. STRECK, BARRETO, OLIVEIRA. "Ulisses e o canto das sereias: sobre ativismos judiciais e os perigos da instauração de um "terceiro turno da constituinte", In: Revista de Estudos Constitucionais, Hermenêutica e Teoria do Direito - RECHTD. 1(2):75-83 julho-dezembro 2009, p. 7.

17 HABERMAS, Jürgen. Direito e Democracia II, p. 304. 
mais transparentes. Assim, a qualidade da interpretação moral da constituição, feita por meio de argumentos baseados em princípios, torna-se fator decisivo não apenas para a legitimidade das decisões em si, mas também para avaliar a legitimidade da atuação judicial no campo da política. Em outras palavras, para a própria definição de uma decisão como sendo 'ativista' ou apenas decorrência da 'judicialização', faz-se necessário uma prévia interpretação de dispositivos abertos e moralmente carregados.

Nessa linha, Dworkin defende uma revisão do conceito de democracia que atribui legitimidade 'democrática' às cortes constitucionais. $\mathrm{O}$ argumento central de Dworkin é de que os grandes casos constitucionais giram em torno de profundas questões de moralidade, e não em torno do simplório argumento de que 'a constituição deve ser deixada como está', como se o texto falasse por conta própria. Para o autor, a interpretação de uma cláusula constitucional moralmente carregada implica realizar uma interpretação plausível da moralidade política que Ihe dá sentido.

Assim, Dworkin traz a moralidade política ostensivamente para o centro do direito constitucional, e lembra que, devido ao intenso conteúdo axiológico dos direitos fundamentais, não é possível argumentar constitucionalmente sem argumentar moralmente. Para falar juridicamente de igualdade, liberdade e dignidade, tem-se de formular juízos morais. ${ }^{18}$ Quando questões envolvendo direitos fundamentais se apresentam, a regra majoritária não é suficiente para a justificação de uma decisão política. É preciso uma interpretação moral que, no atual modelo político brasileiro, deve ser realizada pelo STF como corte constitucional, por meio da argumentação produzida nas suas decisões.

Assim, a própria questão dos limites da interpretação constitucional depende de uma controvérsia política e moral. Seguindo a argumentação de Dworkin, a única objeção substantiva à leitura moral da constituição é a de que ela ofende a democracia ao desafiar a teoria clássica da separação dos poderes. Mas o conceito de democracia

18 Uma das premissas do novo constitucionalismo é o reconhecimento de que as particularidades do Estado constitucional fazem com que toda argumentação constitucional implique uma argumentação moral. Cf. FIGUEROA, La revancha neoconstitucionalista de Grecia contra Roma in Foro Jurídico - Revista de Derecho, Lima, abril de 2010, p. 135. 
constitucional não se satisfaz com a premissa majoritária. Ela exige, daqueles que conduzem e zelam pelo processo democrático, a submissão a determinadas condições capazes de assegurar o ideal status a todos os cidadãos. Para Dworkin, os procedimentos majoritários são uma exigência em virtude de uma preocupação com a igualdade dos cidadãos e não por causa de um compromisso com as metas da soberania da maioria. A democracia não se satisfaz com as decisões tomadas nas instâncias de deliberação majoritária, mas exige, daqueles que conduzem o processo democrático e da sociedade em geral, a submissão a determinadas condições capazes de assegurar o igual tratamento a todos os cidadãos. ${ }^{19}$

Seguindo o argumento de Dworkin, toda disputa sobre a interpretação constitucional é uma disputa substancial que envolve uma definição moral de democracia. A fronteira entre legislar e aplicar o direito, entre as funções clássicas do legislador e do julgador, apenas pode ser determinada com precisão em face aos princípios que demandam interpretação moral. Desse modo, os limites da jurisdição constitucional legítima não são delimitados apenas pelo enunciado diretamente envolvido, mas pela interpretação moral dos princípios subjacentes à prática jurídica. Mas isso não significa que os juízes tenham poder absoluto para impor suas convicções morais. Significa simplesmente que, quando o texto estiver impregnado pela linguagem moral, a leitura moral é o melhor método interpretativo. ${ }^{20}$

19 DWORKIN, Ronald. O Direito da Liberdade. A leitura moral da Constituição norte-americana, p. 26. Segundo Dworkin, duas versões disputam o conceito de democracia: i) uma concepção majoritária, que a define apenas de modo procedimental, e ii) uma concepção mais social (partnership conception) ou substantiva, que vincula o conceito de democracia a exigências de legitimidade. O profundo contraste entre ambas as concepções é revelado de modo ilustrativo no debate norte-americano sobre a compatibilidade entre a democracia e o judicial review. DWORKIN, Ronald. Justice for Hedgehogs. London, England: Harvard University Press, 2011 , p. 384.

20 DWORKIN, Ronald. O Direito da Liberdade. A leitura moral da Constituição norteamericana, p.18. Para uma visão crítica da leitura moral proposta por Dworkin, ver STRUCHINER, Noel; SHECAIRA, Fabio. A distinção entre direito e moral e a distinção moral do direito in Revista de Direito do Estado, ano 7, $n^{\circ} 22,131-145$, jan-mar 2012. Os autores reconhecem, contudo, que a argumentação constitucional baseada em princípios é moral. Não sendo inteiramente institucional e, portanto, não tipicamente jurídica, na argumentação constitucional as razões substantivas (deontológicas e substancialistas) podem prevalecer" (p. 140). Nos limites deste artigo, é impossível discutir a questão de filosofia moral envolvida no caso. Entretanto deixa-se marcado que nem todo objetivismo moral leva a um absolutismo moral. Autores como Habermas, Rawls, Nino e Atienza defendem a superação do relativismo moral subjacente a diversas teorias positivistas, sem contudo recaírem em um absolutismo moral autoritário. Cf. ATIENZA, Manuel. Dos versiones del constitucionalismo. Revista de Estudos Constitucionais, Hermenêutica e Teoria do Direito. RECHTD, jan-jun 2012, p. 32. 
Nessa linha, os limites de atuação das instâncias de deliberação não majoritárias, como a jurisdição constitucional exercida exclusivamente pelo STF, somente podem ser demarcados no caso concreto por meio da análise dos princípios envolvidos. A maleável fronteira entre legislar/criar e aplicar/reproduzir o direito, entre a função do legislador e a do julgador, apenas pode ser determinada em face aos princípios que demandam interpretação moral. Portanto os limites de atuação da corte constitucional e a classificação de uma decisão com o rótulo de "ativista" dependem de uma compreensão moral dos princípios envolvidos no caso.

\section{FILOSOFIA PRAGMÁTICA DA LINGUAGEM E INTERPRETAÇÃO}

CONSTITUCIONAL

Conforme a crítica mais comum ao 'ativismo judicial', as decisões que não respeitam a 'intenção do legislador' supostamente expressa no texto estariam usurpando a função legislativa e colocando em risco a própria democracia. Tal crítica, além de não considerar a especificidade da jurisdição constitucional em comparação às demais instâncias infraconstitucionais, parece também não considerar as implicações da filosofia pragmática da linguagem para a interpretação constitucional e o novo papel das cortes supremas nas democracias atuais.

Com frequência, a reconstrução do texto constitucional realizada pelo STF é acusada de extrapolar os limites da interpretação e "criar normas" para além das palavras do texto. Muitas dessas críticas partem de um pressuposto falso e frequentemente não tematizado no campo jurídico, mas denunciado pela filosofia contemporânea da linguagem, qual seja, a de que as palavras carregam essências e que basta ao intérprete descobri-las e descrevê-las para que elas funcionem como premissas de um raciocínio dedutivo. Essa visão essencialista da linguagem que ainda informa certas teorias positivistas e antipositivistas é ultrapassada pela teoria interpretativista de Dworkin, que compartilha com demais autores pós-positivistas uma versão convencionalista do significado coerente com a pragmática.

Assim, a distinção entre 'reproduzir' e 'criar' não é tão simples como a arraigada concepção essencialista sugere. ${ }^{21}$ A linguagem nunca é algo pré-dado, mas algo 21 NINO, Carlos Santiago. Introdução à análise do direito. São Paulo: Martins Fontes, 
que se concretiza como uso. O direito é expresso em palavras e, na maioria das vezes, é criado pelo uso de palavras. O legislador utiliza uma linguagem natural, o que faz com que a expressão de sua "intenção" esteja limitada pelas falhas que toda linguagem natural apresenta ${ }^{22}$.

Segundo a versão pragmática, a linguagem é mais bem compreendida como uma atividade capaz de exercer pressão sobre o mundo, uma forma de ação, comunicação e 'recriação' no mundo e não apenas 'descrição' do mundo. A rejeição da concepção essencialista da linguagem - realizada por filósofos da linguagem ordinária como o segundo Wittgenstein, J. L. Austin, Grice e Strawson, além de juristas contemporâneos como Santiago Nino e Manuel Atienza - permite pensar a argumentação constitucional em outras bases, sem recair nas velhas teses metafísicas que pressupõem que as palavras usadas pelo legislador descrevem a "essência" ou a "natureza" das entidades do mundo e que aos intérpretes bastaria reproduzi-las. Tal visão pressupõe que existe um significado intrínseco às palavras - como representação de coisas - que independe do uso e da interpretação.

O segundo Wittgenstein é, sem dúvida, o marco dessa nova filosofia pragmática da linguagem. Segundo o autor das Investigações Filosóficas, Santo Agostinho descreve nas Confissões a «imagem da essência da linguagem humana», que restará central para a metafísica ocidental. A concepção agostiniana da linguagem, escreve Wittgenstein, "entende que as palavras denominam objetos - as sentenças são os liames de tais denominações. Nesta imagem da linguagem encontramos as raízes da idéia: toda palavra tem um significado. Este significado é atribuído à palavra. Ele é o objeto que a palavra designa". ${ }^{23}$

Encontra-se aí, portanto, a tese metafísica por excelência, já esboçada por

2010, p. 294. Segundo a tradição filosófica do essencialismo linguístico - que remonta ao Crátilo de Platão -, há um "verdadeiro" e "único" significado das expressões da linguagem, que deve ser captado investigando-se uma misteriosa realidade não empírica. Carnap a chamou de "concepção mágica da linguagem" e Kantorowicz de 'realismo verbal'.

22 NINO, Carlos Santiago. Introdução à análise do direito, p. 291.

23 WITTGENSTEIN, L. Investigações Filosóficas. Tradução de Marcos G. Montagnoli, Revisão: Emmanuel Carneiro Leão. 2. ed. Petrópolis: Vozes, 1996, p. 15. 
Platão ${ }^{24}$ e Aristóteles ${ }^{25}$ e repetida por toda a tradição filosófica ocidental, qual seja, a de que as palavras colam-se, como etiquetas, às respectivas referências. De uma forma ou de outra, ambas postulam a existência de entidades mentais ou «sentimentos do coração ou affectionem animi» ${ }^{26}$ que explicam, por sua vez, a nossa capacidade de estabelecer a comunicação pela linguagem. Tais entidades constituiriam o próprio conteúdo conceitual presente na comunicação.

É em oposição a esta tese que Wittgenstein, assim como fará Austin por meio da noção de 'ato de fala', abandona a análise da proposição como reveladora do significado. O sentido das expressões não deve mais ser buscado na estrutura lógica e semântica das proposições linguísticas. A atenção do filósofo deve se dirigir para unidades de outra ordem que serão, sobretudo, caracterizadas por outros critérios. Os novos critérios são, com efeito, fornecidos pelo uso que se faz da linguagem nos diferentes contextos, ou seja, nas diversas formas de vida da qual se faz parte. Não basta que uma proposição seja analisada segundo suas unidades mínimas de significação, como propõe Frege, por maior que seja a utilidade de uma tal análise. Uma vez que o significado reside em toda a proposição, aí compreendido a maneira segunda a qual é utilizada efetivamente, então, o significado da linguagem natural dependerá, em última análise, do uso que se faz dos enunciados.

O apoio na estrutura fixa dos fatos que estabelecia o elo com a forma lógica da linguagem e permitia a determinação do significado não pode mais ser mantido.

24 A tese fundamental que está por trás da teoria platônica da correspondência entre a linguagem e o ser é a de que o real é conhecido verdadeiramente em si, sem a utilização de palavras, isto é, sem a mediação linguística. A linguagem não é constitutiva da experiência do real, mas apenas um instrumento, com função designativa, utilizado posteriormente para expressar o objeto do pensamento. Sobre a importância das reflexões filosóficas sobre a linguagem para a correta compreensão das teorias da argumentação jurídica, sobre a influente teoria de Robert Alexy e sua recepção no Brasil, ver DE ANDRÉA, Fernando. Robert Alexy, Introdução crítica. Forense Universitária: Rio de Janeiro, 2013, p. 11.

25 A passagem privilegiada pela tradição filosófica foi a de De Interpretatione $I$, 16, em que Arsitóteles estabelece a concepção da linguagem que dominou a filosofia ocidental até Kant. Heidegger cita esta famosa passagem aristotélica no texto "A essência da linguagem". Transcreve-sea aqui com a tradução de Márcia Sá Cavalcanti: "De um lado, os sons da voz são símbolos das disposições da alma, de outro, as marcas escritas o são dos sons da voz. E assim como as letras não são as mesmas para todos, do mesmo modo também os sons. São idênticas em todos as disposições da alma, das quais os sons são os primeiros signos, assim como são também as mesmas coisas, das quais aquelas são imagens". ARISTÓTELES apud HEIDEGGER, Martin. "A essência da linguagem" in A Caminho da Linguagem, Rio de Janeiro: Vozes, 2003, p.160.

26 SANTO AGOSTINHO, Confissões. 14. ed. Petrópolis: Vozes, 1999, p. 31. 
A linguagem não deve mais ser compreendida como um mecanismo referencial, mas sim a partir da multiplicidade de usos que podem ser feitos das palavras e dos enunciados. Isso não significa dizer que o mecanismo referencial é abandonado, mas que ele deve ser situado no interior de um dos usos possíveis da linguagem, ou seja, em um determinado 'jogo de linguagem'. Assim, toda e qualquer determinação do significado de uma expressão é provisória e parcial, visto que dependente do contexto e das regras do jogo de linguagem em questão.

É nesse sentido que Wittgenstein radicaliza o descolamento entre sentido e referência iniciado por Frege. A significação linguística torna-se, a princípio, independente dos fatos; e a referência, por mais abstrata e formal que seja concebida, não terá mais privilégio sobre outros mecanismos de determinação do sentido. O processo de significação desvincula-se, assim, do modelo referencial. Trata-se agora de investigar como a linguagem engendra a significação mesmo na ausência de qualquer referência. Portanto se trata de investigar as diversas formas de vida nas quais os jogos de linguagem têm lugar por meio de noções vagas como 'semelhança de família' e 'caixa de ferramentas'. Com efeito, Wittgenstein substitui termos tradicionais como fato, referência e significado, por expressões metafóricas, pois as ligações analógicas são as mais apropriadas para essa nova forma de reflexão. As metáforas consistem em meios 'precisos' para caracterizar imprecisamente aquilo que é, por essência, impreciso, a saber, o precesso de significação. Afinal, os conceitos não são independentes de nossa ação e apenas ganham consistência e sentido na medida em que estão inseridos numa determinada forma de vida, ou seja, na medida em que são relativos aos usos que deles se faz. A exatidão conceitual torna-se, assim, um atributo do uso.

Esta é, portanto, a 'virada pragmática' de Wittgenstein: o significado de um enunciado depende do uso que se fazs dele nos diversos contextos. Consequentemente, as categorias usadas para avaliar um enunciado não servem para pensar a linguagem concreta, ou seja, a linguagem como ação. Uma vez que a linguagem é compreendida como uma atividade complexa e não apenas como veículo de representação da realidade, então não é mais possível reduzi-la a um conjunto de enunciados, cuja estrutura subjacente poderia ser revelada pela 
investigação lógica. Assim, a linguagem não trata apenas de designar objetos por meio de palavras. O conceito jogo da linguagem acentua que, nos diferentes contextos, seguem-se diferentes regras, podendo-se, a partir daí, determinar o sentido das expressões linguísticas.

A noção de ato de fala desenvolvida por Austin também revela tal dimensão constitutiva da linguagem. A questão do sentido, do significado e da referência é aboradada pelo filósofo da Escola de Oxford de modo inédito e sua originalidade irá abalar certas questões da linguística descritiva e da filosofia tradicional. A compreensão da linguagem não apenas como representação do real, mas como uma performance que constitui o real inaugura uma nova concepção da linguagem humana, especialmente quando analisa o fenômeno da performatividade. ${ }^{27}$

Escreve Austin: «Quando examinamos o que devemos dizer e quando devemos fazê-lo, que palavras devemos usar, em que situação, não estamos examinando simplesmente palavras (ou seus "significados", seja lá o que isso for), mas sobretudo a realidade sobre a qual falamos ao usar essas palavras (...)».28

Além disso, os atos de fala como performances ou atos performativos não podem ser aferidos pelo crítério de verdade ou falsidade. Um performativo não é verdadeiro ou falso, mas possui uma determinada força (ilocucionária e perlocucionária). O performativo é uma "comunicação" que não se limita essencialmente a transportar um conteúdo semântico, mas que constitui uma determinada força de enunciação. Para Austin, a noção de performativo não designa o transporte de um conteúdo de sentido, como se a linguagem fosse um simples veículo da intenção do falante. Ele não descreve qualquer coisa que exista fora da linguagem e antes de si. Um performativo produz ou transforma uma situação, ele opera. E um dos objetivos principais da análise do ato de fala consiste em revelar a força do ato realizado, o seu poder de persuasão, mobilização, transformação, enfim, operação. ${ }^{29}$

27 OTTONI, Paulo. Visão performativa da linguagem. Campinas: Editora Unicamp, 1998, p. 22.

28 AUSTIN, J.L. "A Plea for Excuses" in Philosophical Papers. 3. ed. Claredon Paperbacks, Oxford University Press, 1990, p. 182.

29 DERRIDA, Jacques. Assinatura acontecimento contexto. Margens da Filosofia. Papirus: São Paulo, 1991, p. 363. 
Desse modo, o 'sucesso' de um ato de fala vai muito além dos elementos linguísticos utilizados ou da veracidade das proposições. Um performativo não é realmente verdadeiro nem falso, uma vez que não descreve um fato. Um performativo é feliz ou infeliz, dependendo das circunstâncias e das consequências do ato. E a 'felicidade' de um performativo depende essencialmente de sua força e dos elementos contextuais que, no caso da interpretação jurídica, é altamente institucionalizada. Ao realizar um performativo, uma relação dialógica se estabelece: o locutor se atribui um papel e atribui ao seu ouvinte um papel complementar. O performativo determina obrigações de tal forma que a linguagem acaba funcionando como uma grande instituição que incorpora uma série de papéis convencionais que correspondem aos atos de fala socialmente reconhecidos.

Essa característica de convencionalidade e institucionalidade dos atos de fala faz com que o Direito - a linguagem jurídica - torne-se o campo ideal para explorar a performatividade da linguagem ordinária. Não é por acaso que Austin ilustrou sua teoria com diversos exemplos jurídicos sugeridos por seu colega H.L.A Hart, como o performativo «sim, eu aceito», pronunciado nos casamentos. O jogo de linguagem do direito, com seu caráter institucional fortemente marcado, permite inúmeras aproximações entre o giro linguístico-pragmático da filosofia contemporânea e a virada argumentativa do direito, como se verá a seguir.

\section{VERSÕES PRAGMÁTICAS DA INTERPRETAÇÃO CONSTITUCIONAL}

Segundo a perspectiva pragmática aqui adotada, a linguagem não é mero instrumento de comunicação do conhecimento. Ela é, antes de tudo, condição de possibilidade para a própria constituição do conhecimento como tal. ${ }^{30}$ Assim, contra a filosofia moderna e seu foco na consciência transcendental, a nova compreensão da linguagem mostra que não há consciência sem linguagem, de modo que a tradicional pergunta sobre as condições de possibilidade do conhecimento humano não pode ser respondida sem uma consideração da linguagem humana.

30 OLIVEIRA, Manfredo. Reviravolta Linguístico-pragmática na Filosofia contemporâ-

nea. 3. ed. São Paulo: Edições Loyola, 2006, p. 128. 
Segundo a direção pragmática, falar já é agir e, sobretudo, interagir. ${ }^{31}$ Assim compreendida, a interpretação e a aplicação de um dispositivo constitucional moralmente carregado não se reduzem a um ato de descrição de um significado previamente dado, mas implicam também uma decisão fundamentada com vistas à aceitação do interlocutor dentro de determinadas regras institucionais. Portanto, na argumentação jurídica usada para justificar uma decisão, o julgador exerce uma atividade que não consiste meramente em descrever o significado previamente existente dos dispositivos, mas em reconstruir esses significados usando de outras partes do Direito, em busca do convencimento de seus interlocutores.

Uma vez que se entende que a linguagem ordinária usada pelos textos jurídicos é socialmente construída (e, portanto, pode se alterar no tempo) e que todo ato de interpretação implica reconstruir o significado, então é forçoso reconhecer que a indeterminação de sentido assombra o direito e ameaça suas bases racionais tradicionais. Reconhecer que o direito abriga inúmeros casos de penumbra implica reconhecer a potencial indeterminação de sentido própria da linguagem natural que constitui o direito. Entretanto reconhecer que os sentidos são reconstruídos no processo de interpretação não significa dizer que os textos são radicalmente indeterminados, nem que a linguagem é totalmente arbitrária.

Conforme a teoria do direito de H.L.A. Hart, com forte inspiração em Wittgenstein e J.L.Austin, uma das maiores dificuldades na aplicação das regras é o fato de estas possuírem uma textura aberta, isto é, o fato de que muitos dos conceitos usados nas leis são porosos, o que faz com que toda regra seja potencialmente vaga. ${ }^{32}$ Entretanto, apesar da potencial indeterminação, o direito funciona porque toda regra tem um núcleo de certeza. ${ }^{33}$ Existem traços

31 Para uma visão dialógica da teoria dos atos de fala, ver MARCONDES, Danilo. Para além da Linguagem: performativos implícitos e atos indiretos in Avzaradel (ed.) Sobre a Linguagem e o Pensar. Rio de Janeiro: Casa do Psicólogo, 2012, p.112.

32 Utiliza-se aqui o sentido amplo de "textura aberta" como "potencial indeterminação ou vaguidade da linguagem usada pelo direito". Para uma distinção mais refinada entre textura aberta, lacunas normativas e os fenômenos da sobreinclusão e subinclusão, ver STRUCHINER, Noel. Para Falar de Regras: O positivismo Conceitual como Cenário para uma Investigação Filosófica acerca dos Casos Difíceis do Direito. Rio de Janeiro: PUC-Rio, 2005, p. 108.

33 "Qualquer que seja a estratégia escolhida para a transmissão de padrões de comportamen- 
mínimos de significado incorporados ao uso da linguagem própria ao direito e compartilhados na prática jurídica. ${ }^{34}$

Como Hart bem percebeu, reconhecer as implicacões da pragmática não significa afirmar que o intérprete é livre para atribuir o sentido que lhe aprouver, nem que a intenção do legislador não tenha importância. Simplesmente, o que se passava na mente dos legisladores quando escolheram expressões linguísticas abertas não é um critério decisivo para atribuir significado às suas palavras. Uma vez que o sentido das palavras apenas se concretiza quanto usadas na prática, ${ }^{35}$ a determinação de como essas palavras seriam razoavelmente interpretadas por seus destinatários uso convencional - e as considerações de autoridade (ordem sistêmica, coerência e integridade) podem ter preferência sobre uma suposta 'descrição' da vontade do legislador 'expressa' de forma 'clara' no texto constitucional.

Toda essa complexa relação de significação entre textos, normas e realidade ganha contornos ainda mais problemáticos na jurisdição constitucional. Isto porque uma decisão envolvendo direitos fundamentais na corte constitucional, por melhor fundamentada que se apresente, é sempre o resultado de uma escolha interpretativa sobre um texto moralmente carregado, cujas palavras deixam grande espaço para a reconstrução do significado e para atuações mais ativas dos intérpretes.

Contudo o que a teoria constitucional contemporânea assinala é que este maior espaço para o intérprete implica também uma maior responsabilidade quanto à qualidade da argumentação utilizada para justificar a decisão. Interpretar é construir a partir de algo já dado, portanto, reconstruir. Os textos normativos não são meras sugestões, mas pontos de partida obrigatórios

to, $(. .$.$) estes se mostrarão imprecisos em algum ponto, quando sua aplicação for posta em$ dúvida; terão o que se tem chamado de textura aberta. Até aqui temos apresentado isso, no caso da legislação, como uma característica geral da linguagem humana; a incerteza nas zonas limítrofes é o preço a pagar pelo uso de termos classificatórios gerais em qualquer forma de comunicação referente a questões factuais. Usadas dessa forma, as línguas naturais, como o inglês, tem uma textura irredutivelmente aberta". HART, H.L.A. O Conceito de Direito, São Paulo: Martins Fontes, 2009, p. 166.

34 Segundo Hart, o sistema jurídico não é arbitrário porque, apesar da textura aberta, cujo julgador possui uma margem de escolha, ele tem um núcleo de sentido estabelecido do qual o aplicador não pode se afastar. HART, H.L.A. O Conceito de Direito, p. 186.

35 "The meaning of a word is its use in the language". Wittgenstein, Investigações Filosóficas, $\S 43$, p. 38. 
(convenções dotadas de autoridade) que oferecem limites à construção de sentidos pelo intérprete. Mas também é preciso reconhecer que a reconstrução implícita em toda a interpretação constitucional manipula a linguagem ao ressaltar versões de significado não explícitas, supostamente mais coerentes com os fins e os valores subjacentes à linguagem constitucional. Assim, o intérprete deve abordar os dispositivos constitucionais de modo a explicitar suas versões de significado de acordo com os fins e valores "entremostrados" na linguagem constitucional, e para fazer isso precisa estabelecer "conexões axiológicas" que não estão incorporadas ao texto nem a ele pertencem, mas são construídas durante o processo de interpretação e aplicação do direito. ${ }^{36}$

Considerando o critério do uso convencional das palavras para determinar o sentido das expressões utilizadas pelo legislador constituinte, então se pode concluir que uma interpretação constitucional é, em última análise, uma reconstrução do uso que a prática jurídica - que não se restringe aos juízes - faz sobre o direito como um todo, e não simplesmente uma descrição do material jurídico diretamente envolvido no caso. O direito é sistêmico e suas regras derivam seus significados não somente do proferimento que as originou, mas de outras partes do direito. Por isso, a combinação das normas determinadas pelo legislador com as outras, que já pertencem ao sistema ou que venham a fazer parte dele no futuro, poderá derivar consequências não previstas pelo referido legislador, ou fazer surgir problemas lógicos que não se apresentam nas normas isoladas, mas que aparecem sempre que entram em relação com o restante do sistema jurídico. ${ }^{37}$

A corriqueira identificação entre texto e norma, por exemplo, revela o preconceito do essencialismo linguístico ainda presente na interpretação jurídica. Como ensina o "pai" do pós-positivismo, Friedrich Müller, ${ }^{38}$ textos não são normas, mas os pontos de partida da atividade interpretativa de atribuição de sentidos e consequente construção de normas. Desde 1966 Friedrich Müller desenvolve 36 ÁVILA, Humberto, Teoria dos Princípios. 11. ed. São Paulo: Malheiros, 2010, p. 34.

37 NINO, Carlos Santiago. Introdução à análise do direito. São Paulo: Martins Fontes, 2010, p. 292.

38 A expressão "teoria pós-positivista do direito" aparece pela primeira vez em Juristische Methodik de 1971, para marcar posição contrária tanto às teorias positivistas quanto às antipositivistas do direito. MÜLLER, Friedrich. O Novo Paradigma do Direito. 3. ed. São Paulo: Ed. Revista dos Tribunais, 2013, p. 10. 
uma teoria que "entende o trabalho jurídico como um processo a ser realizado no tempo e os enunciados nas codificações como textos de normas, no sentido da Linguística moderna (i.e. pragmática)". Isto quer dizer, continua Müller, "que a norma jurídica não existe ante casum: o caso da decisão é coconstitutivo. $O$ texto da norma no código legal é (apenas) um dado de entrada do processo de trabalho chamado concretização". ${ }^{39}$ Nesse mesmo sentido, Ávila argumenta que as normas são o resultado da interpretação, são os sentidos construídos a partir da interpretação sistemática de textos normativos. ${ }^{40}$

Nessa linha, a interpretação de textos normativos abertos, como são os dispositivos constitucionais em questão, por ser indissociável de uma argumentação prática moral ${ }_{1}^{41}$ conduz a uma reconstrução do texto constitucional e à consequente criação de normas. Enquanto co-legislador, o intérprete da corte constitucional (sobretudo em face de dispositivos vagos e moralmente carregados) reconstrói o sentido do texto e apresenta novas versões de significado, novas normas. ${ }^{42}$ Diante da abertura textual dos direitos fundamentais, interpretar a Constituição implica necessariamente desenvolver o direito, produzir normas que não existiam ou declarar outras incoerentes com o referencial valorativo do modelo constitucional, tal como atualmente reconstruído pelos diálogos institucionais internos e internacionais. ${ }^{43}$

Nesse sentido discursivo, para além do debate inócuo entre "criar" ou "legislar", o que merece a atenção é a tensão própria ao Estado de Direito e que afeta em cheio a interpretação constitucional: como efetivar os direitos fundamentais e respeitar a autoridade ao mesmo tempo? Como ressaltam vários autores não positivistas - como Ronald Dworkin, Robert Alexy, Santiago Nino, Manuel Atienza e Neil MacCormick -, os sistemas jurídicos constitucionalizados estão atravessados

39 MÜLLER, O Novo Paradigma do Direito, p. 10.

40 ÁVILA, Humberto. Teoria dos Princípios, p. 30.

41 Para uma crítica ao modelo pragma-dialético elaborado por van Eemeren y Grootendorst, na esteira do diálogo racional de Alexy, com regras para avaliar a racionalidade da argumentação, ver ATIENZA, EI Derecho como argumentación. Barcelona: Ariel Derecho, 2006, p. 268.

42 ÁVILA, Humberto. Teoria dos Princípios. p. 30.

43 Sobre a vinculação entre diálogo institucional e deliberação para a atribuição de legitimidade representativa às cortes constitucionais, ver MENDES, Conrado Hubner. Direitos Fundamentais, Separação de Poderes e Deliberação. São Paulo: Saraiva, 2011. 
por uma tensão entre a realização da justiça e o respeito à autoridade. Esta tensão traz para a jurisdição constitucional uma difícil conciliação entre um papel ativo, porém limitado pelo sistema jurídico. ${ }^{44}$

Assim, dizer que a jurisdição constitucional tem a responsabilidade de reconstruir dispositivos moralmente carregados não significa dizer que as cortes constitucionais sempre tomam as melhores ou mais corretas decisões. ${ }^{45}$ Significa apenas dizer que, entendido como um ato de fala complexo, como um ato ilocucionário institucionalizado, a argumentação judicial produzida pela corte constitucional não é um simples procedimento formal, dependente de uma idealizada clareza do texto constitucional. Mesmo uma expressão "clara" pode ganhar contornos imprecisos quando interpretada à luz dos referentes valorativos que informam os princípios constitucionais reconstruídos e afirmados pelos tribunais pátrios. ${ }^{46}$ Uma vez que o caráter sistêmico do Direito exige reconhecer que o significado das regras jurídicas não deriva apenas do proferimento que o originou, mas também de outras partes do sistema jurídico, então outros fatores podem tornar o direito vago, mesmo quando as palavras usadas não o eram.

Considerando a inexorável abertura do texto, a interpretação constitucional realizada pelas cortes aproxima-se de uma atividade social, dialógica e intersubjetiva, um processo de deliberação que ergue pretensões de correção e

44 ATIENZA, 'Dos versiones del constitucionalismo'. Revista de Estudos Constitucionais, Hermenêutica e Teoria do Direito (RECHTD), jan-jun 2012, p. 35.

45 A adesão a um constitucionalismo pós-positivista a partir de uma leitura de Dworkin, Alexy, Nino e Atienza, não implica a adesão ao realismo jurídico ou a uma visão instrumentalista do direito. O reconhecimento da dimensão normativa do direito (axiológica ou valorativa), sem a qual a noção de direito fundamental não pode ser compreendida, não desconhece o sistema baseado em fontes, não precisa de uma distinção forte entre regras e princípios, não reduz a metodologia jurídica à ponderação e não pressupõe um objetivismo moral intolerante. Portanto a tese da conexão intrínseca entre direito e moral defendida por tais autores não significa desprezar a autoridade do sistema, mas apenas reconhecer uma dimensão de valor no âmago do direito e as novas funções das cortes constitucionais diante das democracias atuais. A partir de tal constatação, interpretar o direito significa, a partir do material jurídico proveniente da autoridade que é dado ao intérprete, esforçar-se por encontrar o sentido que conduza ao melhor desenvolvimento dos valores que informam a prática jurídica, prática esta que não se restringe aos juízes, mas se estende aos advogados, legisladores, gestores públicos, teóricos e 'dogmáticos' do direito, etc. Cf. ATIENZA, Dos versiones del constitucionalismo, p. 31-35.

46 Por exemplo, o rechaço da interpretação "clara" ou convencional - a contrario sensu - das expressões "homem e mulher" contidas no $\S 3^{\circ}$ do art. 226 da CF/88 foi argumento central na Adpf 132 sobre o casamento homoafetivo. 
coloca em discussão os fins e os valores da sociedade em questão. ${ }^{47}$ Por carregar tamanha responsabilidade, também carrega um maior ônus argumentativo que nem sempre resgata, como as inúmeras críticas à atuação do STF comprovam.

Mas o que importa aqui destacar é a virada hermenêutica do direito e o reconhecimento de que sua prática está banhada em argumentação. Uma vez que é organizada por uma série institucionalizada de procedimentos discursivos, toda posição jurídica implica uma pretensão de correção que deve ser justificada por argumentos controláveis por um auditório capaz de entender as razões aduzidas e de ser persuadido por elas. Como prática argumentativa, os participantes do jogo do direito, no momento mesmo que se engajam na atividade interpretativa, têm de estar dispostos a atender à exigência de cooperar uns com os outros na busca de razões aceitáveis para os outros; e, mais ainda, têm de estar dispostos a deixar-se afetar e motivar, em suas decisões afirmativas e negativas, por essas razões e somente por elas.

Nesse sentido, o caráter argumentativo do direito não é a antítese do Estado de Direito - e do império da lei com suas regras claras -, mas um de seus componentes. Nem sempre se tem certeza e segurança sobre os resultados, mas se tem certeza e segurança de que certos procedimentos argumentativos serão seguidos. ${ }^{48}$ Portanto as teorias da argumentação jurídica também possuem argumentos políticos a seu favor, visto que são tentativas de enfrentar o desafio colocado pelo desenvolvimento democrático, ou seja, atender às demandas sociais em relação às decisões jurídicas (opinião pública) e manter a estabilidade e a integridade do sistema normativo (autoridade).

Independente de ser considerada "regulatória" ou "principiológica", 49 é forçoso reconhecer que a Constituição Brasileira de 1988 é um texto amplo e generoso, repleto de promessas de 'estados ideais de coisas' que deixam enorme margem para a reconstrução criativa do intérprete, como demonstra a jurisprudência

47 Sobre o caráter social da argumentação a partir de uma perspectiva pragmática, ver ATIENZA, EI Derecho como argumentación, p. 256.

48 MAcCORMICK, Neil. Retórica e o Estado de Direito. Rio de Janeiro: Elsevier, 2008, p.17.

49 ÁVILA, Humberto. Neoconstitucionalismo: entre a "ciência do direito" e o "direito da ciência. 
constitucional dos últimos 20 anos. Poucos negariam que a CF/88 é uma Carta dirigente e que preza por valores como dignidade, liberdade, igualdade e não discriminação. Entretanto entendimentos muito diferentes de tais expressões são compatíveis com a linguagem, os precedentes e a história de nossa prática jurídico-constitucional. O que pode gerar legítimas divergências de interpretação, ou seja, diferentes reconstruções de sentido dos enunciados normativos diante dos casos concretos. Mas a indeterminação de dispositivos principiológicos e o fato do pluralismo moral das democracias atuais não justificam a autocontenção da corte constitucional, especialmente quando se tratar de garantir os direitos fundamentais de minorias derivados de uma leitura moral da Constituição.

Expressões como "dignidade", "igualdade" e "interesse público" significam muito pouco antes da intervenção do intérprete no caso concreto. Textos são diferentes de normas e, quanto mais vagos e indeterminados, maiores as possibilidades de reconstruções e as mutações de sentido, de acordo com o desenvolvimento da própria linguagem queé, por sua vez, uma construção social. Assim, a derrotabilidade das regras demonstrada pela prática das cortes constitucionais democráticas revela a transformação do direito, da linguagem e da sociedade..$^{50}$

Nesse sentido, hoje não se trata mais de determinar como é o direito atual - mera descrição do material jurídico -, mas de determinar como ele deve ser reconstruído da forma mais 'fiel' possível. ${ }^{51}$ Nas palavras de Dworkin: "dizer como as coisas são significa, até certo ponto, dizer como elas devem ser". ${ }^{52}$ No entanto grande parte da teoria jurídica brasileira continua a desconsiderar as implicações da máxima da visão pragmática - não essencialista e não mentalista - da linguagem de que toda interpretação implica uma reconstrução de sentido.

Atienza identifica muitas das falácias do raciocínio jurídico não apenas nos erros de inferência (falácias formais), mas nas falácias materiais causadas exatamente

50 Como exemplo dessa dinâmica entre o texto, seus possíveis sentidos e a realidade, ver os casos de mutação constitucional presentes na ADIN 186 e na ADPF 132 tal como trabalhados por BOTELHO, Nadja. Mutação Constitucional - A Constituição viva de 1988. Rio de Janeiro: Lumen Juris, 2011.

51 FIGUEROA, Alfonso. La revancha neoconstitucionalista de Grecia contra Roma, p.141.

52 DWORKIN, Ronald. O Direito da Liberdade. A leitura moral da Constituição norte-americana, p. 59. 
pela concepção essencialista da linguagem que leva o intérprete a pensar que há um verdadeiro significado dos termos usados. Dessa maneira, o intérprete parte de uma premissa falsa (com aparência de ser verdadeira e correta) irrelevante para a conclusão. Por exemplo, quando pretende defender uma interpretação estritamente literal de um dispositivo. ${ }^{53}$

Portanto a abertura concedida ao intérprete pela versão pragmática da linguagem não conduz a uma completa desconsideração das palavras usadas pelo legislador. Adotar uma visão pragmática da linguagem não implica desconsiderar os limites semânticos do texto, mas apenas reconhecer que os critérios da semântica não são suficientes para a interpretação constitucional. ${ }^{54}$ É preciso levar em conta o convencionalismo linguístico e a reconstrução do sentido realizada pelo intérprete na argumentação com base em direitos fundamentais. Como lembra Nino, "os tribunais não podem alterar, apagando ou riscando, o que está escrito em um texto legal, mas podem, sim, adaptar o significado das expressões linguísticas a usos linguísticos diferentes dos seguidos pelo legislador". ${ }^{55}$

\section{NOTAS CONCLUSIVAS: ATIVISMO, DEMOCRACIA E DIREITOS} FUNDAMENTAIS

As teorias da interpretação/argumentação jurídica baseadas na versão pragmática da linguagem aqui apresentadas com apoio em autores como Alexy, Müller e Dworkin não simplesmente exaltam a importância dos princípios e da ponderação, além de não menosprezar a importância das regras na prática do direito. ${ }^{56}$ Não é preciso defender uma caracterização da Constituição Brasileira como principiológica para aceitar que a teoria clássica da separação dos poderes

53 ATIENZA, Manuel. El Derecho como argumentación, p. 274

54 Para uma visão mais aprofundada da filosofia pragmática da linguagem, que não se confunde com o pragmatismo, nem desconsidera a semântica, ver MARCONDES, Danilo. A Pragmática na Filosofia Contemporânea. Rio de Janeiro: Jorge Zahar editor 2005. Para uma crítica do ramo analítico da filosofia da linguagem que "deu continuidade à teoria do conhecimento por outros meios", desconsiderando as implicações do ramo hermenêutico da virada linguística, ver HABERMAS, Jürgen. Verdade e Justificação. São Paulo: Edições Loyola, 2004, p. 10.

55 NINO, Carlos Santiago. Introdução à análise do direito, p. 292.

56 Para uma crítica a certo "neoconstitucionalismo", ver ÁVILA, Humberto. Neoconstitucionalismo": entre a "ciência do direito" e o "direito da ciência, p. 10. 
e da democracia representativa como mero "princípio majoritário" não serve mais como critério para avaliar a atuação das cortes constitucionais nas democracias pluralistas contemporâneas. Também não é preciso aceitar acriticamente o 'paradigma da ponderação' para reconhecer que a Carta de 1988 está repleta de cláusulas gerais e moralmente carregadas.

O que todos estes autores, muitas vezes classificados como pós-positivistas, apontam é que, para além do rótulo de ativista, a correção da decisão do STF não pode ser desvinculada da disputa (moral) sobre o conceito de democracia. $A$ interpretação constitucional, isto é, a reconstrução do sentido do texto constitucional por meio da argumentação, especialmente quando se trata de dispositivos moralmente carregados, não se esgota na semântica, ou seja, na exegese das frases usadas nos textos legais. Toda decisão e justificação jurídicas precisam fazer considerações pragmáticas relativas ao uso convencional das palavras e ao seu significado perante outras partes do direito e perante o contexto.

Nesse sentido, considerando as implicações da nova forma de se compreender a linguagem constitucional e a função das Cortes superiores no atual paradigma deliberativo da Democracia e do Direito, muitas das críticas formuladas ao STF não se sustentam. Por exemplo, a crítica de que a corte constitucional não tem legitimidade para "criar" lei porque os ministros não são representantes diretos do "povo" se dissolve perante a versão deliberativa da jurisdição constitucional, seja ela classificada como ativista ou não. ${ }^{57}$ Uma vez que o juiz da corte constitucional é colegislador, então sua função de 'representante argumentativo' - ou de deliberador - não pode mais ser compreendida nos moldes do constitucionalismo liberal pré-democratização. ${ }^{58}$

Além disso, ao reconhecer e assumir a responsabilidade política de garantir a concretização dos princípios constitucionais, especialmente a igualdade de

57 Até mesmo teorias procedimentalistas como de Hart Ely, que desconfiam da compatibilidade entre a democracia e a revisão judicial e que defendem uma versão limitada de controle judicial, acabam por reconhecer a legitimidade da revisão judicial por razões de substância. DWORKIN, Ronald. Justice for Hedgehogs, p. 384.

58 Sobre a necessidade de uma revisão do conceito de representação para além do critério majoritário, ver POGREBINCHI, Judicialização ou Representação? Rio de Janeiro: Elsevier, 2012. 
consideração e respeito de todos os cidadãos, o Supremo Tribunal Federal apenas desempenha sua vocação de instituição com potencial para enriquecer a qualidade argumentativa da democracia e propiciar uma interlocução institucional desejável nos complexos estados de direito contemporâneos.

Contudo, para concretizar o nobre sonho de conciliação entre direitos fundamentais e soberania popular, superando o aparente conflito entre jurisdição constitucional e democracia, é preciso que a leitura moral defendida por Dworkin seja abertamente reconhecida por meio de argumentos baseados em princípios e não em slogans superficiais ou "inúteis metáforas sobre equilíbrio e estrutura". ${ }^{59}$

As críticas procedimentalistas às decisões ativistas do STF, ao partirem de uma visão estreita da separação de poderes não mais condizente com as democracias constitucionais, continuam utilizando o slogan do ativismo e acabam não oferecendo nenhuma objeção substancial sobre a argumentação utilizada, nem sobre as demais razões relevantes para a decisão. Nesse sentido, não ajuda no controle da adequação dos argumentos utilizados nem no estabelecimento de critérios para a legítima atuação democrática de uma corte constitucional. Apenas mantém o jogo de oposições de rótulos vagos, como 'ativismo versus judicialização', como se fosse possível uma definição prévia dos limites de atuação da corte constitucional.

Buscando superar essa dicotomia, este artigo articulou diversas teorias e autores no intuito de incrementar um discurso de legitimidade capaz de reconhecer a posição política da corte constitucional no atual desenho institucional brasileiro. Em outras palavras, buscou destacar a importância de atualizar nosso modo de pensar a relação entre ativismo judicial, democracia deliberativa e a interpretação constitucional envolvendo direitos fundamentais.

\section{REFERÊNCIAS}

ARGUELHES, Diego Werneck. "Carta criou STF poderoso que muda dinâmica política", Artigo Jornal Valor - 3 de outubro de 2013. Disponível em: http://www.bresserpereira.org.br/ terceiros/2013/outubro/13.10.STF_poderoso.pdf

59 DWORKIN, Ronald. O Direito da Liberdade. A leitura moral da Constituição norte-americana, p.22. 
ARGUELHES, Diego Werneck. "Poder não é querer: preferências restritivas e redesenho institucional no Supremo Tribunal Federal pós-democratização". In: SARMENTO (Coord.). Jurisdição Constitucional e Política. Rio de Janeiro: Forense, 2015.

ÁVILA, Humberto. Teoria dos Princípios. São Paulo: Malheiros, 11 ed., revista, 2010.

ÁVILA, Humberto. "Neoconstitucionalismo": entre a "ciência do direito" e o "direito da ciência". Revista eletrônica de Direito do Estado (REDE), Salvador, Instituto Brasileiro de Direito Público, n.17, janeiro/fevereiro/março, 2009. Disponível na Internet: http://www.direitodoestado.com. br/rede.asp. Acesso em: 30 junho de 2012.

ATIENZA, Manuel. 'Dos versiones del constitucionalismo'. Revista de Estudos Constitucionais, Hermenêutica e Teoria do Direito (RECHTD), jan-jun 2012.

ATIENZA, Manuel. El Derecho como argumentación. Barcelona: Ariel Derecho, 2006.

AUSTIN, J. (1962) How to do Things with words. Cambridge: Harvard University Press, 1975.

AUSTIN, J. (1956) "A Plea for Excuses" in Philosophical Papers, Third Edition, Claredon Paperbacks, Oxford University Press, 1990.

AUSTIN, J. (1958) "Performatif-Constatif". In: La Philosophie Analytique - Cahiers de Royaumont, tradução de Paulo Roberto Ottoni, 1997, in Visão performativa da linguagem. Campinas: Editora Unicamp, 1998.

ALEXY, Robert. Constitucionalismo Discursivo. Porto Alegre: Livraria do Advogado, 2008.

ALEXY, Robert."Ponderação, Jurisdição Constitucional e Representação Popular" In: SOUZA NETO; SARMENTO. (Orgs.). A Constitucionalização do Direito. Rio de Janeiro: Lumen Juris, 2007.

AZEVEDO CAMPOS, Carlos Alexandre. Dimensões do Ativismo Judicial do STF. Rio de Janeiro: Forense, 2014.

BARROSO, Luís Roberto. "Constituição, Democracia e Supremacia Judicial: Direito e Política no Brasil contemporâneo". Revista Jurídica da Presidência, v. 12, n. 96. Brasília: fevereiromaio de 2010 .

BARROSO, Luís Roberto. Curso de Direito Constitucional Contemporâneo. São Paulo: Saraiva, 2015. 576 p. 
BARROSO, Luís Roberto. Judicialização, ativismo judicial e legitimidade democrática. (2008) http://www.oab.org.br/editora/revista/users/revista/ 1235066670174218181901.pdf.

BOTELHO, Nadja. Mutação Constitucional - A Constituição viva de 1988. Rio de Janeiro: Lumen Juris, 2011. 228 p.

CAPPELLETTI, Mauro. O controle judicial de constitucionalidade das leis no direito comparado. 2. ed. Porto Alegre: Fabris, 1999.

CONTINENTINO, Marcelo Casseb. "Ativismo Judicial: considerações críticas em torno do conceito no contexto brasileiro". Revista de Direito do Estado - RDE, ano 5, n. 19-20, jul/dez 2010.

DE ANDRÉA, Fernando. Robert Alexy, Introdução crítica. Rio de Janeiro: Forense Universitária, 2013.

DERRIDA, Jacques. "Assinatura acontecimento contexto". In: Margens da Filosofia, Papirus, São Paulo, 1991. ("Signature événement contexte", in Marges de la Philosophie. Les Éditions de Minuit, Paris, 1972).

DWORKIN, Ronald. O Direito da Liberdade. A leitura moral da Constituição norteamericana. São Paulo: Martins Fontes, 2006.

DWORKIN, Ronald. O Império do Direito. São Paulo: Martins Fontes, 2003.

DWORKIN, Ronald. Justice for Hedgehogs. London, England: Harvard University Press, 2011.

ELY, John Hart. Democracia e Desconfiança. Uma teoria do controle Judicial de Constitucionalidade. São Paulo: Martins Fontes, 2010.

FIGUEROA, Alfonso. Criaturas de la Moralidad. Madrid: Ed. Trotta. 2009.

FIGUEROA, Alfonso. "La revancha neoconstitucionalista de Grecia contra Roma" in Foro Jurídico - Revista de Derecho, Lima, abril de 2010.

GARAPON, Antoine. O juiz e a democracia. O guardião das promessas. Rio de Janeiro: Revan, 2001.

HABERMAS, Jürgen. Direito e Democracia. Rio de Janeiro: Tempo Brasileiro, 1997.

HABERMAS, Jürgen. O discurso Filosófico da Modernidade. São Paulo: Martins Fontes, 2000. 
HABERMAS, Jürgen. Verdade e Justificação. São Paulo: Edições Loyola, 2004.

HÄBERLE, Peter. Hermenêutica Constitucional; Sociedade Aberta dos Intérpretes da Constituição: contribuição para a interpretação pluralista e procedimental da Constituição. Porto Alegre: Fabris, 1997.

HART, H.L.A. O Conceito de Direito. São Paulo: Martins Fontes, 2009.

HEIDEGGER, Martin. O Caminho da Linguagem. Rio de Janeiro: Vozes, 2003.

MARCONDES, Danilo. A Pragmática na Filosofia Contemporânea. Rio de Janeiro: Jorge Zahar editor, 2005.

MARCONDES, Danilo. Filosofia, Linguagem e Comunicação. 3. ed. São Paulo: Cortez Editora, 2000.

MARCONDES, Danilo. "Para além da Linguagem: performativos implícitos e atos indiretos" In: AVZARADEL (Ed.). Sobre a Linguagem e o Pensar. Rio de Janeiro: Casa do Psicólogo, 2012. MacCORMICK, Neil. Argumentação Jurídica e Teoria do Direito. São Paulo: Martins Fontes, 2006.

MacCORMICK, Neil. Retórica e o Estado de Direito. Rio de Janeiro: Elsevier, 2008.

MARMOR, Andrei. "A natureza do direito". Trad. Lucas Miotto. Revista Direito, Estado e Sociedade, $n^{\circ}$ 42. PUC-Rio, Jun/Jan 2013.

MAUS, Ingeborg. "Judiciário como superego da sociedade: o papel da atividade jurisprudencial na sociedade órfã". Novos Estudos CEBRAP, no. 58, Novembro de 2000.

MENDES, Conrado Hübner. Direitos Fundamentais, separação de poderes e deliberação. São Paulo: Saraiva, 2012.

MENDES, Conrado Hübner. Constitutional Courts and Deliberative Democracy. Oxford, 2013.

MÜLLER, Friedrich. O Novo Paradigma do Direito. 3. ed. São Paulo: Ed. Revista dos Tribunais, 2013.

OLIVEIRA, Manfredo. Reviravolta Linguístico-pragmática na Filosofia contemporânea. 3. ed. São Paulo: Edições Loyola, 2006.

OTTONI, Paulo. Visão performativa da linguagem. Campinas: Editora Unicamp, 1998. 
NINO, Carlos Santiago. Introdução à análise do direito. São Paulo: Martins Fontes, 2010.

POGREBINSCHI, Thamy. Judicialização ou Representação? Rio de Janeiro: Campus/Elsevier, 2012.

SANTO AGOSTINHO, Confissões. 14. ed. Petrópolis: Vozes, 1999.

SGARBI, Adrian. Introdução à teoria do direito. Marcel Pons, 2013.

STRUCHINER, Noel. Para Falar de Regras: O positivismo Conceitual como Cenário para uma Investigação Filosófica acerca dos Casos Difíceis do Direito. Rio de Janeiro: PUC-Rio, 2005.

STRUCHINER, Noel. "Indeterminação e objetividade: quando o direito diz o que não queremos ouvir", In Macedo Jr. e Barbieri. Direito e Interpretacão. São Paulo: Saraiva, 2011.

STRUCHINER, Noel. "Posturas Interpretativas e modelagens institucionais: a dignidade (contingente) do Formalismo". In: SARMENTO, D. (Coord.). Filosofia e teoria constitucional contemporânea. Rio de Janeiro: Lúmen Júris, 2009.

STRUCHINER e SHECAIRA, "A distinção entre direito e moral e a distinção moral do direito". In: Revista de Direito do Estado, ano 7, n²2, 131-145, jan-mar 2012.

SARMENTO, Daniel. "Interpretação constitucional, Pré-compreensão e Capacidades Institucionais do Intérprete". In: SARMENTO, D. (C oord.) Vinte Anos da Constituição Federal de 1988. Rio de Janeiro: Lúmen Júris, 2009.

SARMENTO, Daniel. "Ubiqüidade constitucional: os dois lados da moeda", In SOUZA NETO; SARMENTO. (Orgs.). A Constitucionalização do Direito. Rio de Janeiro: Editora Lumen Juris, 2007.

WITTGENSTEIN, L. Investigações Filosóficas. Tradução de Marcos G. Montagnoli, Revisão: Emmanuel Carneiro Leão. 2. ed. Petrópolis: Vozes, 1996.

Recebido em: jun/2015

Aprovado em: nov/2015 